\title{
Erratum to "Some common fixed point theorems in Menger PM spaces"
}

M Imdad ${ }^{1}$, M Tanveer ${ }^{2}$ and $M$ Hasan $^{3^{*}}$

* Correspondence: hasan352000@gmail.com ${ }^{3}$ Department of Applied Mathematics, Aligarh Muslim University, Aligarh 202 002, India Full list of author information is available at the end of the article
On critical examination of the results given in our paper [1], we notice some minor errors except a crucial one. In all, we need to carry out the following corrections:

1. Following condition must be added to statement of Lemma 3.1 and Theorem 3.3. (*) $B\left(y_{n}\right)$ converges for every sequence $\left\{y_{n}\right\}$ in $X$ whenever $T\left(y_{n}\right)$ converges (or $A\left(x_{n}\right)$ converges for every sequence $\left\{x_{n}\right\}$ in $X$ whenever $S\left(x_{n}\right)$ converges).

2. Theorem 3.13 follows in view of Example 2.2 and Theorem 3.5, and henceforth an independent proof is not required as given in [1].

3. Remarks 3.6 and 3.10 are not relevant to the results as claimed in respective remarks and hence stand deleted.

4. The following typing errors are noticed in Examples 3.16 and 3.17:

(i) 'In Examples 3.16 and 3.17 " $a, b \in[0,2)$ " should be " $a, b \in[0,1]$ ",

(ii) in Example 3.16. ' $A(X)=\{1\} \subset\{1,2 / 3\}=S(X)$ " should be " $A(X)=\{1\} \subset\{1,1 / 3\}=$ $T(X)$ ",

(iii) in Example 3.17 " $A(X)=\{1,3 / 4\} \nsubseteq\{1,2 / 3\}=S(X)$ " should be " $A(X)=\{1,3 / 4\}$ $\Phi\{1,1 / 3\}=T(X)$ " and

(iv) in Example 3.17 " $B(X)=\{1,1 / 2\} \nsubseteq\{1,1 / 3\}=T(X)$ " should be " $B(X)=\{1,1 / 2\}$ $\nsubseteq\{1,2 / 3\}=S(X)$.

\section{Acknowledgements}

All the authors are grateful to Prof. Dorel Mihet for pointing out some of these errors.

\section{Author details}

'Department of Mathematics, Aligarh Muslim University, Aligarh 202 002, India ${ }^{2}$ School of Computer \& Systems

Sciences, Jawaharlal Nehru University, New Delhi 110 067, India ${ }^{3}$ Department of Applied Mathematics, Aligarh Muslim University, Aligarh 202 002, India

Received: 6 May 2011 Accepted: 10 August 2011 Published: 10 August 2011

\section{Reference}

1. Imdad, M, Tanveer, M, Hasan, M: Some common fixed point theorems in Menger PM spaces. Fixed Point Theory Appl, Art. ID 81926914 (2010).

doi:10.1186/1687-1812-2011-28

Cite this article as: Imdad et al: Erratum to "Some common fixed point theorems in Menger PM spaces". Fixed Point Theory and Applications 2011 2011:28.

\section{SpringerOpen ${ }^{\circ}$}

(c) 2011 Imdad et al; licensee Springer. This is an Open Access article distributed under the terms of the Creative Commons Attribution License (http://creativecommons.org/licenses/by/2.0), which permits unrestricted use, distribution, and reproduction in any medium, provided the original work is properly cited. 